\title{
Antibiotic Conformity with Culture Results of Hospitalized Pneumonia Patients in Melati Ward at Dr. Hasan Sadikin General Hospital Bandung, Indonesia
}

\author{
Randhi Rinaldi,, ${ }^{1}$ Yana Akhmad Supriatna, ${ }^{2}$ Truly Sitorus, ${ }^{3}$ Primal Sudjana ${ }^{2}$ \\ ${ }^{1}$ Faculty of Medicine Universitas Padjadjaran, ${ }^{2}$ Department of Internal Medicine Faculty of \\ Medicine Universitas Padjadjaran/Dr. Hasan Sadikin General Hospital Bandung, ${ }^{3}$ Department of \\ Pharmacology and Therapy Faculty of Medicine Universitas Padjadjaran
}

\begin{abstract}
Background: Pneumonia is an infection with the highest mortality rate in Indonesian hospitals. According to The American Thoracic Society and The Infectious Diseases Society of America (ATS/IDSA), empirical use of antibiotics is still effective for pneumonia treatment. Inappropriate use of antibiotics would cause negative effects such as prolonged hospitalization, a high cost of treatment, and increased antibioticresistant bacteria. The goal of this study was to clarify the empirical use of antibiotic conformity with a bacteria culture.

Methods: This study was conducted from August to October 2013 using a descriptive retrospective method based on 116 medical records of pneumonia patients hospitalized in Melati Ward, Dr. Hasan Sadikin General Hospital Bandung during 2011-2012. The type of bacteria, conformity with antibiotics given to patients, and type of antibiotics were analyzed. The conformity of antibiotics was assessed based on the resistance test. If the results were sensitive, they would be put in the conforming group and in the non-conforming group if the results were resistant or intermediate. Data was derived with descriptive statistics, using percentage and frequency distribution, illustrated in tables and figures.

Results: Based on culture results and sensitivity of antibiotic empirical therapy given, 55.17\% cases were conformed. The most widely used antibiotic group was Third-generation Cephalosporin (60.34\%). The most common bacterias were Klebsiella pneumonia (34.5\%) and Acinetobacter baumanni (13.8\%).

Conclusions: Most of the antibiotics given to pneumonia patients are still appropriate with results of the bacteria culture test and resistance test. [AM].2016;3(4):504-8]
\end{abstract}

Keywords: Antibiotic, conforming group, nonconforming group, Klebsiella pneuomonia, pneumonia

\section{Introduction}

Pneumonia is the inflammation of the distal parenchyme lung from terminalis bronchioles; it also includes respiratory bronchiolus, which causes lung tissue consolidation and the filling of alveoli by the inflammation exudate and the fibrin. ${ }^{1}$

Pneumonia is still a severe problem with high morbidity and mortality. ${ }^{2,3}$ There are a wide variety of bacteria that cause pneumonia, depending on how pneumonia is transmitted. Pneumonia infections have the highest mortality rate in Indonesian hospitals. ${ }^{4}$

Antibiotics are used to treat pneumonia. Around $80-90 \%$ of antibiotics are used as treatment and prophylaxis for infection in clinics and hospitals, contributing to antibiotic resistance and one of the causes of the high mortality rate. ${ }^{5,6}$ According to the guidelines from The American Thoracic Society and the Infectious Diseases Society of America, empirical use of antibiotic is still effective to treat pneumonia. ${ }^{2}$ Whenever the patient had been diagnosed of pneumonia, they have to be hospitalized to be given the appropriate antibiotic empirical therapy. ${ }^{7-9}$ The inappropriate use of antibiotics causes negative consequences such as prolonged hospitalization, a high cost of treatment, and increased antibiotic resistance in bacteria. ${ }^{10}$

Therefore, the goal of this study was to

Correspondence: Randhi Rinaldi, Faculty of Medicine, Universitas Padjadjaran, Jalan Raya Bandung-Sumedang Km.21, Jatinangor, Sumedang, Indonesia, Phone: +62 81214494374 Email: randhirinaldi@gmail.com 
clarify the conformity results of antibiotics with the bacteria culture in hospitalized pneumonia patients in Melati Ward at Dr. Hasan Sadikin General Hospital, Bandung from 2011-2012.

\section{Methods}

This study was conducted during AugustOctober 2013 and used a descriptive retrospective method. The population of the study was all medical records of pneumonia patients who were hospitalized in Melati Ward representing theInternal Medicine Department at Dr. Hasan Sadikin General Hospital, Bandung during 2011-2012. Pneumonia was defined based on chest radiography proof of a new pulmonary infiltrate, and at least two of the following symptoms and signs. There were cough, pleuritic chest pain, shortness of breath, temperature $>38^{\circ} \mathrm{C}$, and crackles on auscultation..$^{10}$ Medical records from this study subjects served as the secondary data. Data was collected by used of the total sampling method.

The samples were all subjects that had the complete data and all the variables. Furthermore, the type of bacteria, their conformity with antibiotics given to the patients, and type of antibiotics were analyzed variables in this study.

The inclusion criteria were medical records of hospitalized patients with a diagnosis of pneumonia that had gone through the sensitivity test culture and were given medicine as written in the medical records. While medical records with incomplete data were excluded. Out of 478 medical records of pneumonia patients, only 116 medical records met the inclusion criteria.

Next, the conformity was grouped into a conforming and non-conforming group. The conformity of antibiotics was assessed based on the resistance test. If the results were sensitive, they would be put in the conforming group and in the non-conforming group if the results were resistant or intermediate.

Moreover, data was derived with descriptive statistics, using percentage and frequency calculations by the Microsoft Excel software (Version 2010); the results of the study were illustrated in tables and figures.

This study had been approved by the Health Research Ethics Committee, Faculty of Medicine, Universitas Padjadjaran, Dr. Hasan Sadikin General Hospital.

\section{Results}

Of the 116 patients who were given antibiotics, $55.17 \%$ were given the antibiotics that conformed with the bacteria culture test. The antibiotics that were appropriate with the gram-negative bacteria were $53.25 \%$, while $59.46 \%$ were appropriate with gram-positive bacteria and $50 \%$ for the other bacteria (Figure 1).

The predominantly used antibiotic groups

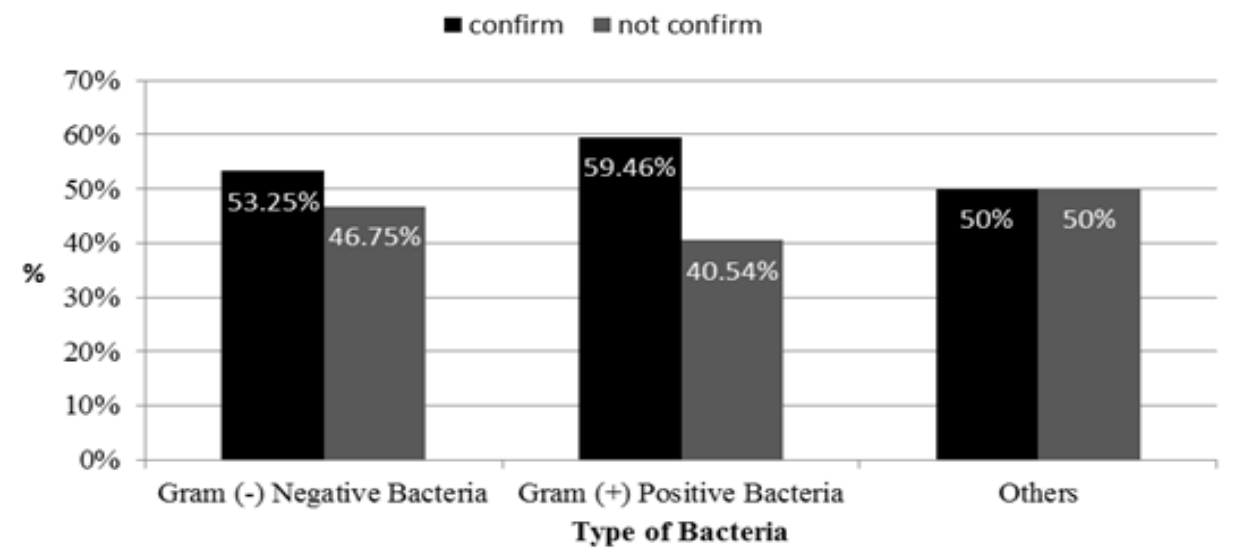

Figure 1 Bacteria Distribution and Resistance Test of Culture Results in Hospitalized Pneumonia Patients at Melati Ward in Dr Hasan Sadikin Hospital Bandung 20112012 
Randhi Rinaldi, Yana Akhmad Supriatna, Truly Sitorus, Primal Sudjana: Antibiotic Conformity with Culture 505 Results of Hospitalized Pneumonia Patients in Melati Ward at Dr. Hasan Sadikin General Hospital Bandung

Table 1 Antibiotic Groups Distribution and Resistance of Culture Results in Hospitalized Pneumonia Patients at Melati Ward in Dr. Hasan Sadikin Hospital Bandung 2011-2012

\begin{tabular}{|c|c|c|c|c|c|c|}
\hline \multirow{2}{*}{ Antibiotic Groups } & \multicolumn{2}{|c|}{ Conforming } & \multicolumn{2}{|c|}{ Non-conforming } & \multirow{2}{*}{$\Sigma$} & \multirow{2}{*}{$\%$} \\
\hline & $\mathbf{n}$ & $\%$ & $\mathbf{n}$ & $\%$ & & \\
\hline Third-Generation Cephalosporin & 36 & 51.43 & 34 & 48.57 & 70 & 60.34 \\
\hline Fluoroquinolone & 18 & 54.55 & 15 & 45.45 & 33 & 28.45 \\
\hline Macrolide & 6 & 85.71 & 1 & 14.29 & 7 & 6.03 \\
\hline Carbapenem & 2 & 100.00 & 0 & 0.00 & 2 & 1.72 \\
\hline Penicillin & 0 & 0.00 & 1 & 100.00 & 1 & 0.86 \\
\hline Fourth-Generation Cephalosporin & 1 & 100.00 & 0 & 0.00 & 1 & 0.86 \\
\hline Second-Generation Cephalosporin & 0 & 0.00 & 1 & 100.00 & 1 & 0.86 \\
\hline Aminoglycoside & 1 & 100.00 & 0 & 0.00 & 1 & 0.86 \\
\hline$\Sigma$ & 64 & 55.17 & 52 & 44.83 & 116 & 100 \\
\hline
\end{tabular}

were Third-Generation Cephalosporin in 70 patients $(60.34 \%)$, followed by Fluoroquinolone in 33 patients $(28.45 \%)$. The antibiotic groups that were most appropriate were Third-Generation Cephalosporin $(51.43 \%)$, followed by Fluoroquinolone (54.55\%), based on the results of the resistance culture (Table 1).

The antibiotic was given due to the sign and symptom from patients that indicated pneumonia. The use of broad-spectrum antibiotics was still used as an empirical therapy before the culture test was performed, to determine the definitive therapy.

Furthermore, antibiotics given to the hospitalized Pneumonia patients were Ceftazidime 50/116 (43.1\%), followed by Levofloxacin 26/116 (22.4\%), Ceftriaxone 10/116 (8.6\%), Cefotaxim 9/116 (7.8\%), Ciprofloxacin and Erythromicin 7/116 (6.0\%) (Figure 2).

The culture results of hospitalized pneumonia patients showed that the predominant type of bacteria was Gram

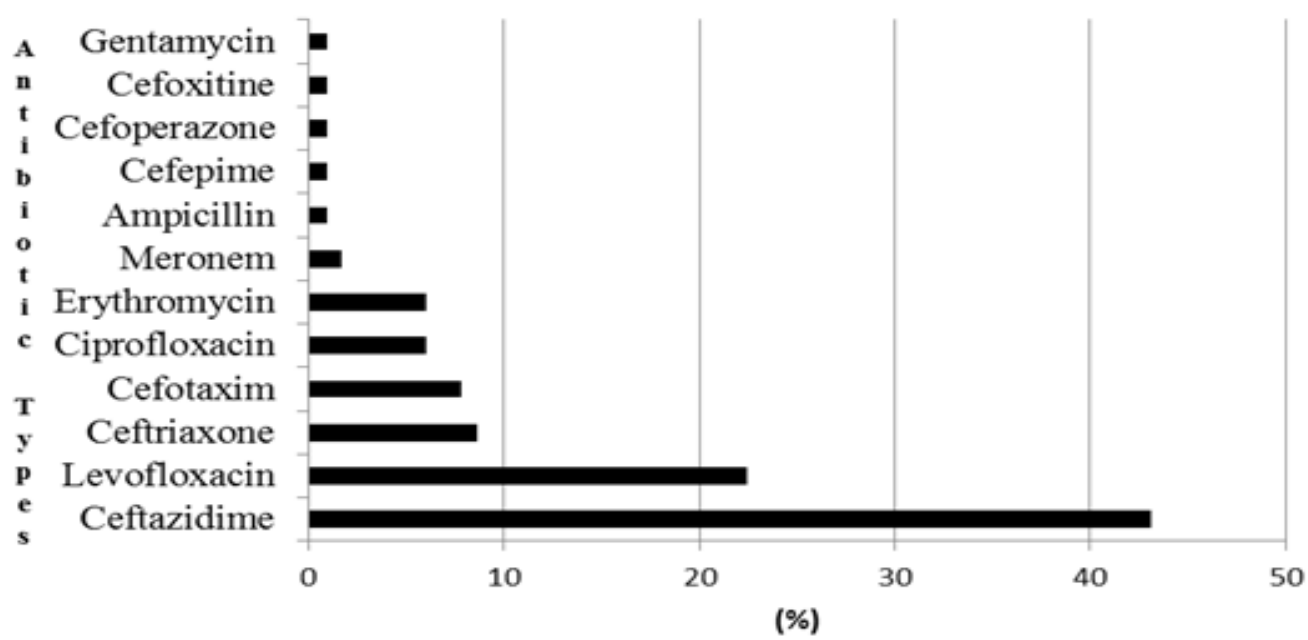

Figure 2 Distribution of Antibiotic Types Used on Hospitalized Pneumonia Patients at Melati Ward in Dr Hasan Sadikin Hospital Bandung 2011-2012 


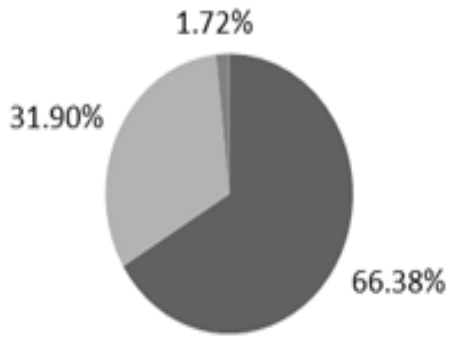

- Gram (-) Negative Bacteria

m Gram (+) Positive Bacteria

athers

Figure 3 Bacteria Distribution on Hospitalized Pneumonia Patients at Melati Ward in Dr Hasan Sadikin Hospital Bandung 2011-2012

negative (-) bacteria (66.38\%) (Figure 3).

The predominant types of bacteria were Klebsiella pneumonia 40/116 (34.5\%), followed by Acinetobacter baumannii 16/116 $(13.8 \%)$ (Figure 4).

\section{Discussions}

Pneumonia can occur in the primary tissue of normal lung tissue or in abnormal lung tissue. It could also be an advanced phase of Acute Lower Respiratory Tract Infection. The etiology of pneumonia depends on the type of pneumonia. Bacteria characteristics that cause pneumonia depend on the patient's context of exposure to pollution, immunity disturbance, and irrational use of antibiotics. ${ }^{1,11}$

Based on the results of specimen cultures from this study, the predominant sources of Gram-negative bacteria were Klebsiella pneumonia, followed by Acinetobacter baumannii (13.8\%). Only 6.0\% were from the Gram-positive bacteria Staphylococcus aureus..$^{12} \mathrm{~A}$ study about pneumonia prevalence in Asian Countries by Chung et al. ${ }^{6}$ in 2011, also stated the predominant causes of pneumonia are Acinetobacter spp (36.5\%), Pseudomonas aeruginosa (25.9\%), and Klebsiella pneumonia $(16.8 \%)$, all of which are Gram-negative bacteria; only $12.2 \%$ is caused by the Grampositive bacteria Staphylococcus aureus.

According to the 2007 guidelines of the

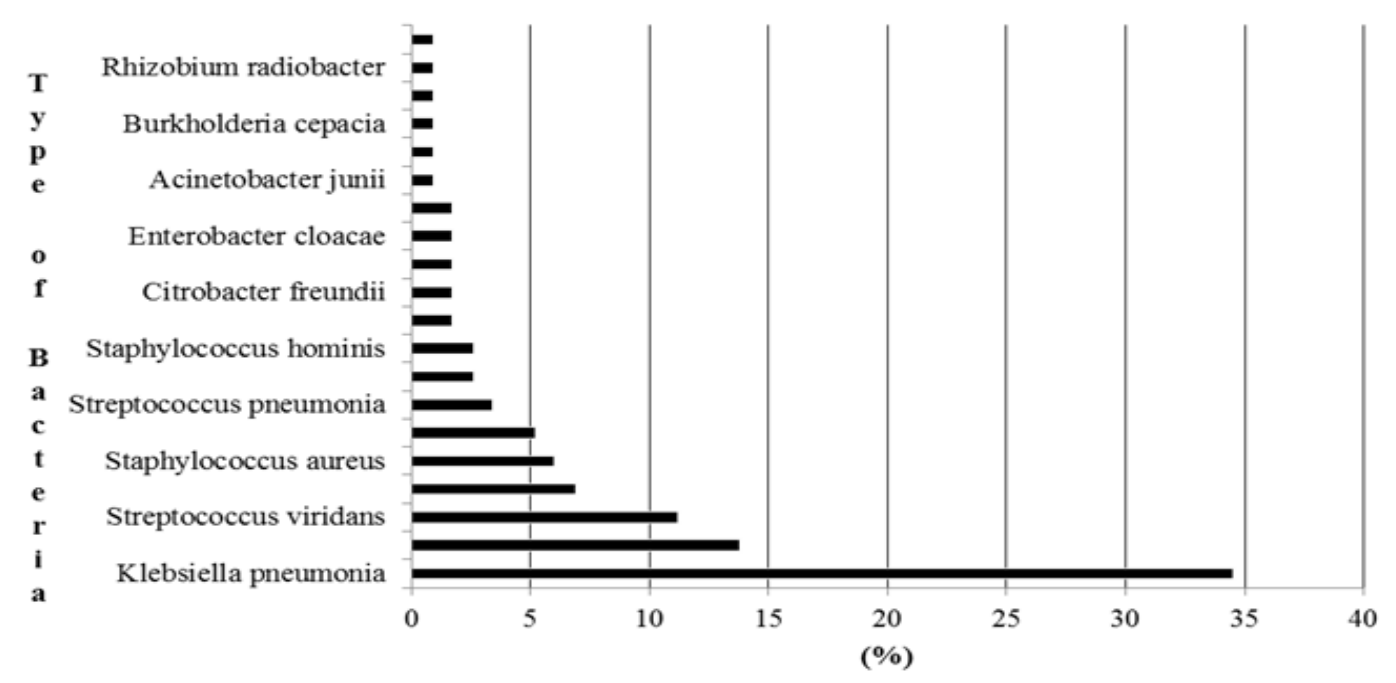

Figure 4 Distribution of Pneumonia Bacteria Type in Hospitalized Pneumonia Patients at Melati Ward in Dr Hasan Sadikin Hospital Bandung 2011-2012 
Randhi Rinaldi, Yana Akhmad Supriatna, Truly Sitorus, Primal Sudjana: Antibiotic Conformity with Culture 507 Results of Hospitalized Pneumonia Patients in Melati Ward at Dr. Hasan Sadikin General Hospital Bandung

Infectious Disease Society of Taiwan on the use of antibiotics for pneumonia, infections of Klebsiella pneumonia, Sterptococcus pneumoniae, Pseudomonas aeruginosa and Acinetobacter spp are best treated with Thirdgeneration cephalosporin (or Fluoroquinolone as the alternative).$^{13}$ In this study, 70 out of 116 patients $(60.34 \%)$ were given Thirdgeneration cephalosporin antibiotics, and 33 out of $116(28.45 \%)$ patients were given fluoroquinolone. The results showed that the empirical use of antibiotics on the Pneumonia patients supported the guidelines from the Infectious Disease Society of Taiwan. ${ }^{13}$

It isimportant to consider, giving ceftazidime for the empirical treatment of hospitalized pneumonia patients is equivalent in term of efficacy and is well tolerated. Nevertheless, the use of fluroquinolone needs a tighter supervision to prevent the complication that might happen or the treatment can be substituted with tigecycline as an alternative. ${ }^{14}$

The empirical antibiotic therapy should be considered with the condition of the patients, monitoring of microbial pathogens and bacterial resistance are possible things to avoid bacterial resistance. ${ }^{15}$

This study had several limitations. First, data were obtained only from one hospital; this might not reflect the overall antibiotics conformity. Also, there were some missing data from the medical records.

In conclusion, most of the empirical use of antibiotics are still appropriate. The most given antibiotics are Third-generation Cephalosporin and Fluoroquinolone group, which are Ceftazidime and Levofloxacin. Based on this study, the prominent bacteria that caused pneumonia was Gram Negative (-) Bacteria, which were Klebsiella pneumonia and Acinetonacter baumannii. Therefore, Ceftazidime and Levofloxacin can still be used as the empirical antibiotics in Dr. Hasan Sadikin General Hospital.

\section{References}

1. Mandell LA, Wunderink R. Pneumonia. In: Longo DL, Kasper DL, Jameson JL, Fauci AS, Hausen SL, Loscalzo J. Harrison's principles of internal medicine. 18th ed. New York: McGraw-Hill; 2008.

2. Kett DH, Cano E, Quartin AA, Mangino JE, Zervos MJ, Peyrani P, et al. Implementation of guidelines for management of possible multidrug-resistant pneumonia in intensive care: An observational, multicentre cohort study. Lancet Infect
Dis. 2011;11(3):181-9.

3. Jennie JDE, Sumit M, Yan MAJ, Thomas M. Long-term morbidity and mortality after hospitalization with community-acquired pneumonia: a population-based cohort study. Medicine. 2008;87(6):329.

4. Ministry of Health Republic Indonesia. Indonesia Health Profile 2010. In: Brahim R, Sitohang V, Zulkarnaen I, editors. 2011 health status situation. Jakarta: Ministry of Health Republic Indonesia; 2011. p.40-1

5. Bisht RKA, Singh R, Mittal P. Antibiotic resistance-A global issue of concern. Asian J Pharm Clin. 2009;2(2):34-9.

6. Chung DR, Kim SH, Thamlikitkul V, Huang SG, Wang H, So TM, et al. High prevalence of multidrug-resistant nonfermenters in hospital-acquired pneumonia in Asia. Am J Respir Crit Care Med. 2011;184(12):140917.

7. Peleg AY, Cooper HD. Hospital-acquired infections due to gram-negative bacteria. N Engl J Med. 2010;362(19):1804-13.

8. Brito V, Niederman MS. Healthcareassociated pneumonia is a heterogeneous disease, and all patients do not need the same broad-spectrum antibiotic therapy as complex nosocomial pneumonia. Curr Opin Infect Dis. 2009;22(3):316-25.

9. Siegel RE. Emerging gram-negative antibiotic resistance: Daunting challenges, declining sensitivities, and dire consequences. J Am Assoc Respir Care. 2008;53(4):471-9.

10. Ott SR, Hauptmeier BM, Ernen C, Lepper PM, Nüesch E, Pletz MW, et al. Treatment failure in pneumonia: impact of antibiotic treatment and cost analysis. Eur Respir J. 2012;39(3):611-8.

11. Brooks GF, Carroll KC, Butel JS, Morse SA. Jawetz, Melnick, \& Adelberg's medical biology. 24th ed. New York: McGraw-Hill Medical, 2007. p.223-44.

12. Chan YJ, Chang SC, Chang FY, Chen PY, Chen YC, Chuang YC, et al. Guidelines on antimicrobial therapy of pneumonia in adults in Taiwan, revised 2006. J Microbiol Immunol Infect. 2007;40:279-83.

13. Carratala J, Mykietiuk A, Fernandez-Sabe $\mathrm{N}$, Suarez C, Dorca J, Verdaguer R. Health care-associated pneumonia requiring hospital admission. Arch Intern Med. 2007;167(13):1393-9.

14. Tanaseanu C, Milutinovic S, Calistru PI, Strausz J, Zolubas M, Chernyak V, et al. Efficacy and safety of tigecycline versus levofloxacin for community-acquired pneumonia. BMC Pulm Med. 2009;9(1):44. 
15. Hashemian SMR, Tabarsi P, Mohammad MM, Marjan M, Shamei M, Nadji SA, et al. A prospective study of antibiotic susceptibility in patients with ventilator associated pneumonia. Anaesth Pain \& Intensive Care. 2012;16(1):31-7. 